\title{
ANTI-STREPTOLYSIN O TITRE IN RHEUMATIC CARDITIS
}

\author{
BY \\ E. N. CHAMBERLAIN, C. A. ST. HILL, AND S. COPE \\ From the Royal Southern Hospital, Liverpool \\ Received August 28, 1957
}

The definition of rheumatic fever has been broadened of recent years and many people take it to include not only articular and skin manifestations but also all those signs that are commonly regarded as evidence of an active carditis. While this conception may be pathologically correct and at times convenient in use, it is clear that there are many cases of rheumatic fever where there is no proof of cardiac involvement and equally others where rheumatic involvement of the heart is evident without the other features of the rheumatic state.

The commonly held view that rheumatic fever is the sequel of a streptococcal infection led to the investigation of immune bodies produced by these streptococci amongst which are to be numbered the anti-streptolysins, anti-fibrolysin, and anti-hyaluronidase. In spite of modern diagnostic aids, recognition of the presence of rheumatic activity, especially in the heart, remains a problem of great difficulty. It seemed to us, therefore, that it was important to re-assess the various criteria by which rheumatism and rheumatic carditis are at present judged. Although most of our observations have embraced clinical, electrocardiographic, radiological, biochemical, and bacteriological investigations, the present report is devoted to the anti-streptolysin O titre (A.S.O.).

Our series differs from those of most hitherto published work in the length of observations made in the individual patient. The clinical and certain other observations have continued over several years. The anti-streptolysin studies extend over a period of many months and sometimes more than a year. Estimations were made fortnightly with an average of 12 for each patient.

Among previous studies of the anti-streptolysin O titre there is considerable variation in what should be accepted as normal. Rantz et al. (1952) gave figures of 150 for children between the ages of five and seven, and of 184 for those between eight and twelve. Faver (1953) regarded the level as normal below 200 and thought that when there was a rise above this level it was due to previous streptococcal infection. Denny et al. (1950) recorded a higher titre in those cases that developed rheumatic fever, while Rantz et al. (1948) found the titre lower in those who develop carditis than in those with joint pains. More recently Stollerman et al. (1956) accepted 200 as the upper limit of normal.

A great variation is also found in the type of the curve, which generally rose in one to two weeks and was maximal in four weeks (McCarty, 1952; and Bywaters, 1951). There was a conflict of opinion as to whether a rise always occurs when a patient develops rheumatic fever. Rantz et al. (1952), Bywaters (1951), McCarty (1952), and Todd (1932) suggest that this is so, but Chaptal et al. (1954), Faber (1953), Poppi (1952), Windblad et al. (1949), and Waksman (1949) deny it.

An opinion has been expressed partly on the basis of the anti-streptolysin $O$ titre that rheumatic fever is streptococcal in origin. This view is held by Long (1954), Faber, Poppi, Bywaters, and Denny et al. (1950) but not by Waksman. The only specific references to the relationship of this titre to chorea since 1946 are by Poppi (1952) and Taranta and Stollerman (1956). In many of these papers a study of the erythrocyte sedimentation rate (E.S.R.) was made concurrently with the A.S.O., and Windblad et al. (1949) find the curves to be parallel. 
Source of Material. Most of our observations were made upon children in St. Joseph's Heart Hospital, Rainhill, where children ranging in age from five to eighteen years continue their medical supervision and education often for several years. It gave us an unusual opportunity, therefore, of watching the development of cases of rheumatic carditis and noting the fluctuations in the disease from year to year. Most children are admitted to the hospital some time after the acute rheumatic process has subsided, but there is often information from other hospitals about the findings when the children were under their care. Some children were admitted when there was still doubt as to whether the carditis had completely settled and some developed further episodes of the rheumatic state or of carditis while they were in St. Joseph's.

When it was deemed justifiable each child was brought to the Royal Southern Hospital for a comprehensive clinical, electrocardiographic and radiological review. The blood specimens for the anti-streptolysin $O$ titre and throat swabs were also brought to the Pathology Department of this hospital.

There were generally about forty children at St. Joseph's, but a few of these had congenital heart disease and only served as controls. The number of rheumatic cases was, however, increased by the addition of some admitted directly to the Royal Southern Hospital and to the Liverpool Regional Cardiac Centre, though generally these children were older. Later in the investigations one of us (S.C.) was able to add observations on children in Alder Hey hospital. In all 72 cases were investigated.

In view of the distance between the Convalescent Heart Hospital, St. Joseph's and the central hospitals in the city, it was not always possible to synchronize the investigations as we would have wished. The regular estimation of the anti-streptolysin $O$ titres was, however, paralleled by an estimation of the E.S.R. and by throat swabs. Electrocardiograms were also available at regular intervals, and the clinical observations on the rheumatic and cardiac signs were made by two of us (E.N.C. and S.C.) in conjunction with Dr. D. M. Freeman, so that each child was generally seen at least once a week and more frequently in the event of a change in the condition. We were thus able in general to chart the variations of the A.S.O. titre against rheumatic signs, such as articular rheumatism and nodules, against fever, whether of rheumatic or non-rheumatic origin, and against the presence of active carditis. The technique for estimation of the A.S.O. titre was that described by Rantz and Randall (1945) using streptolysin O produced by the Wellcome Research Laboratories.

\section{RESULTS}

Quiescent Cases (Table I). In many cases the level of the anti-streptolysin $\mathrm{O}$ titre was as low as 12 and quite often 50: these figures would by any standards be accepted as normal. There was, however, a considerable number with a titre ranging from 150 to 250 , in which it was difficult to show any parallelism between this and any manifestation of the rheumatic state.

The 18 controls included two cases that had a history of rheumatic fever, two years previously in one and six months previously in the other, but no heart lesion; in these the anti-streptolysin $\mathrm{O}$ titre levels ranged from 100 to 250 . In eight other cases of established valvular heart disease in whom no evidence of recent rheumatic activity or of streptococcal infection had been recorded (from periods varying from four months to nine years) the titres were generally below 180 , occasionally up to 250 and in two cases (M.H. and J.F.) up to 350. The reason for levels above the accepted normal was obscure, though there may have been a cryptic streptococcal infection, but it emphasizes the importance of admitting a large variation in titre as having no relationship either to rheumatic fever or rheumatic carditis. The remaining controls were provided by following the titres of eight children with congenital heart disease (not shown in the Table). In these cases likewise a variation of the titre from levels of 12 to 250 was noted.

With these figures as a basis it appeared that the best way of assessing the significance of any rise in titre in relation to rheumatic carditis was to determine whether any patterns exist and compare them with the pattern in caditis. We have attempted to do this in relationship to: (1) controls, 
(2) rheumatic fever, (3) chorea, (4) rheumatic carditis, (5) fever not attributable to the rheumatic state, and (6) congestive cardiac failure.

Rheumatic Fever (Table II). This term has been used here to denote the fifteen cases of fever accompanied principally by articular manifestations but also by rheumatic nodules or rashes. It was in those with joint manifestations that the highest figures for the A.S.O. titre (500-1250) were found. In several instances when the clinical course of the illness was short, even though the attack was sharp, there was an early rise and rapid fall in the A.S.O. titre roughly corresponding with the clinical pattern.

In our small series no significant difference was observed between the figures in the first or subsequent attacks of rheumatic fever. The mean level of the rise and fall of the anti-streptolysin $\mathrm{O}$ titre is seen in the Figure, but there are considerable variations, more apparent in the Tables. In the three cases with only minor rheumatic manifestations, the A.S.O. titre figures were

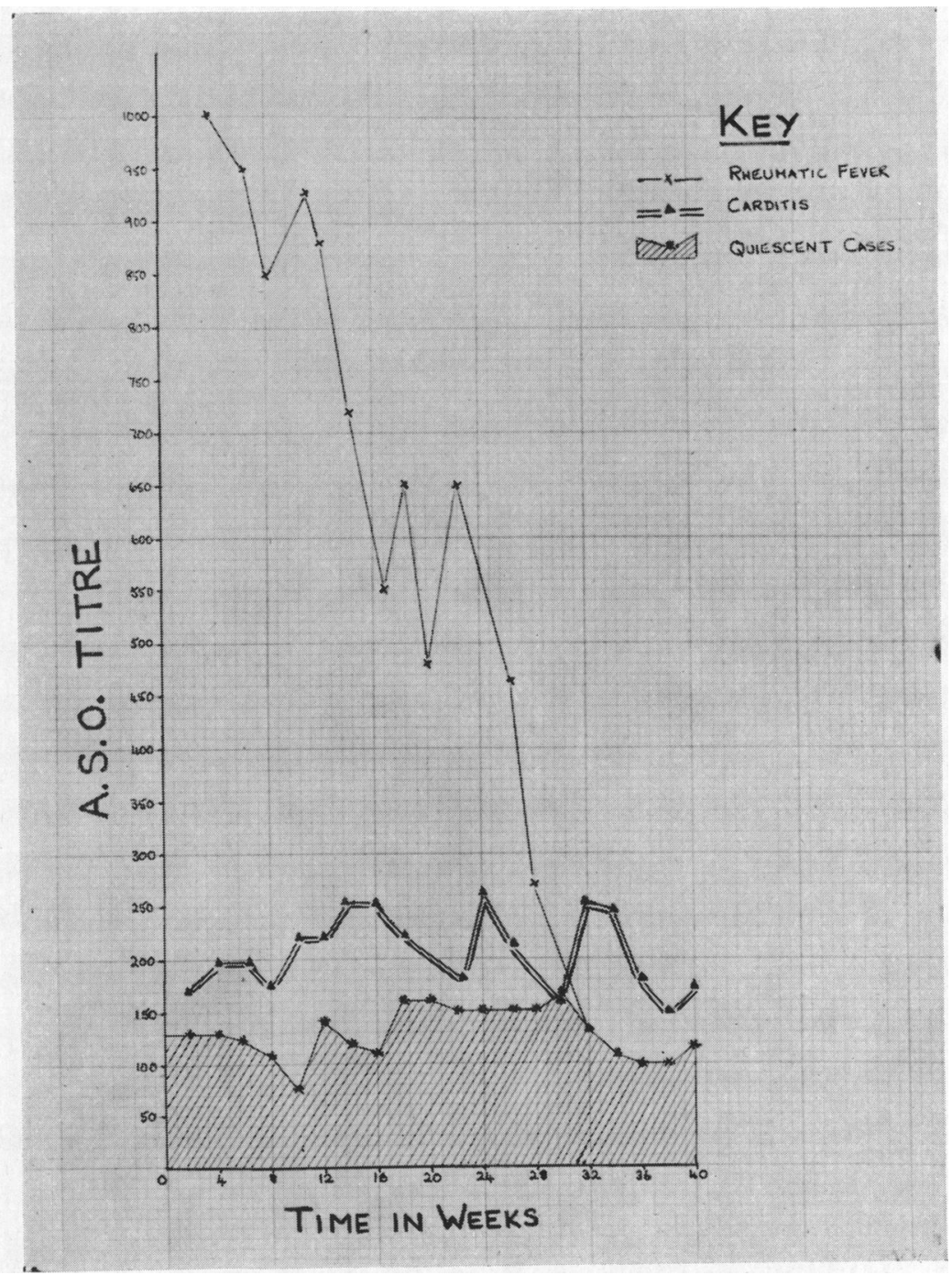

FIG. 1.-Mean rate of fall of anti-streptolysin $O$ titre in cases of rheumatic fever compared with those with rheumatic carditis and quiescent cases. 
TABLE I

Quiescent CASES

\begin{tabular}{l|r|r|r|r|r|r|r|r|r|r|r|r|r}
\hline \multirow{2}{*}{ Name } & \multicolumn{10}{|c|}{ Titre during 26 weeks of the observation period } \\
\cline { 2 - 9 } & $0-2$ & $2-4$ & $4-6$ & $6-8$ & $8-10$ & $10-12$ & $12-14$ & $14-16$ & $16-18$ & $18-20$ & $20-22$ & $22-24$ & $24-26$ \\
\hline * D. C. & 250 & & 250 & & 180 & 250 & 100 & 180 & 250 & & 180 & & \\
\hline * J. L. & 250 & 180 & 180 & 125 & 125 & 180 & 250 & 125 & & & & & \\
\hline J. McD. & 180 & & 180 & 125 & 50 & 180 & 125 & 50 & 180 & 250 & 250 & 100 & 180 \\
\hline M. H. & 250 & 250 & 180 & 180 & 250 & 250 & 250 & 250 & 250 & 250 & 350 & 350 & 350 \\
\hline P. A. & 12 & 12 & 12 & 12 & 12 & 12 & 12 & 12 & 12 & 12 & 12 & 12 & 12 \\
\hline J. F. & 180 & 125 & 250 & 100 & 50 & 180 & 100 & 180 & 350 & 180 & 125 & 350 & 180 \\
\hline G. W. & 180 & 180 & 50 & 50 & 12 & 180 & 50 & 50 & 125 & 125 & 100 & 50 & 12 \\
\hline M. H. & 250 & 250 & 250 & 180 & 125 & 125 & 180 & 180 & 250 & 250 & 250 & 250 & 180 \\
\hline J. H. & 50 & & 100 & & & 50 & 50 & 12 & 12 & 50 & 12 & 50 & 50 \\
\hline B. O'C. & 180 & 180 & 50 & 50 & 12 & 180 & 100 & 50 & 125 & 125 & 180 & 100 & 125 \\
\hline
\end{tabular}

* All patients had valvular disease of the heart except these two who had no organic disease.

TABLE II

Cases of Uncomplicated Rheumatic Fever

\begin{tabular}{l|r|r|r|r|r|r|r|r|r|r|r|r|r}
\hline Name & \multicolumn{1}{|c|}{$2-4$} & $4-6$ & $6-8$ & $8-10$ & $10-12$ & $12-14$ & $14-16$ & $16-18$ & $18-20$ & $20-22$ & $22-24$ & $24-28$ & $28-30$ \\
\hline Y. L. K. & 1250 & 500 & 900 & 350 & & & & & & & & 180 & \\
\hline K. M. & & & & & & 125 & 100 & 100 & 50 & 50 & 50 & 50 & 50 \\
\hline A. I. & & & 620 & 900 & & 1250 & 1250 & 1250 & 1250 & 1250 & 1250 & 900 & 500 \\
\hline M. McG. & & 900 & 900 & 500 & 250 & & 620 & 620 & & 500 & & & \\
\hline G. B. & 125 & 350 & 1250 & & & & & & & & & & \\
\hline P. M. & 1250 & & 1250 & & 1250 & & & & & & & & \\
\hline C. Sa. & & 1250 & 1250 & 1250 & 1250 & 1250 & & & & & & & \\
\hline A. H. & 1250 & 900 & 500 & 1250 & 1250 & 1250 & & & & & & & \\
\hline D. O. & 1250 & 1250 & 900 & 1250 & & & & & & & & & \\
\hline J. St. & & & 900 & 500 & 350 & 900 & 900 & & & & & & \\
\hline A. G. & 1250 & 1250 & 1250 & 500 & & & & & & & & & \\
\hline J. Ba. & & 1250 & 1250 & 900 & & 500 & & 250 & & 125 & & & \\
\hline M. A. & 1250 & 1250 & & 900 & 900 & 900 & & & & & & & \\
\hline M. As. & 1250 & 1250 & 900 & 900 & 900 & & & & & & & & \\
\hline J. H. & 1250 & 1250 & 900 & 900 & 1250 & & & & & & & & \\
\hline
\end{tabular}


comparatively low. The presence or absence of carditis did not appear to modify the A.S.O. pattern.

Chorea (Table III). Only twelve cases of chorea came under observation, a number inadequate to justify any firm conclusions. Our figures, however, support the observations of Poppi (1952) and Taranta and Stollerman (1956) who found that titres may be normal in chorea. They were normal in 5 of our cases, though in the remaining 7 they reached the level found in articular rheumatic fever. In cases where the titre was raised this might occur early or late in the disease. In this observation our results differed somewhat from those of Taranta and Stollerman who considered that the immunological responses in chorea may be declining as the disease appears: they claim that often the disease makes its appearance several months after other rheumatic manifestations. Table III shows the wide variation in patterns that may occur in chorea.

TABLE III

Cases of Chorea (UnComplicated)

\begin{tabular}{l|r|r|r|r|r|r|r|r|r|r|r}
\hline & \multicolumn{10}{|c}{ Weeks after onset of disease } \\
& $2-4$ & $4-6$ & $6-8$ & $8-10$ & $10-12$ & $12-14$ & $14-16$ & $16-18$ & $18-20$ & $20-22$ & $22-26$ \\
\hline D. B. & 250 & 180 & 125 & 180 & 125 & 125 & 125 & 180 & 125 & 180 & 350 \\
\hline G. N. & & 50 & 12 & 50 & 50 & 50 & 50 & 50 & 50 & 50 & 50 \\
\hline J. B. & & 500 & 620 & 900 & 1250 & & & & & & \\
\hline J. K. & 1250 & 900 & 620 & 620 & & & & & & & \\
\hline J. S. & 1250 & 1250 & 1250 & 1250 & 900 & 900 & 500 & 500 & 350 & 620 & 620 \\
\hline
\end{tabular}

Rheumatic Carditis (Table IV). This is the group of cases in which we had particularly hoped for information. So that a comparison can easily be made, Table IV sets out examples of the A.S.O. titre in carditis alone, in carditis with rheumatic fever, and in carditis with chorea. In all 25 cases have been scrutinized. In fourteen of these we felt justified in regarding the diagnosis as certain; of these, eleven had other manifestations of rheumatism. The cardiac signs accepted as evidence of

TABLE IV

Cases with Carditis

\begin{tabular}{|c|c|c|c|c|c|c|c|c|c|c|c|c|c|c|c|c|c|c|c|c|c|}
\hline \multirow{2}{*}{ Name } & \multirow{2}{*}{$\begin{array}{c}\text { Other } \\
\text { rheumatic } \\
\text { manifestation }\end{array}$} & \multicolumn{20}{|c|}{ Weeks after the onset of disease } \\
\hline & & $0-2$ & $2-4$ & $4-6$ & $6-8$ & $8-10$ & $|10-12|$ & $12-14$ & $|14-16|$ & $16-18$ & $18-20$ & $20-22$ & $22-24$ & 24-26 & $26-28$ & $828-30$ & $30-32$ & $32-34$ & $|34-36|$ & $|36-38|$ & $38-40$ \\
\hline A. T. & Nil & \multicolumn{20}{|c|}{ varying from 180 to 250} \\
\hline B. $\mathrm{H}$. & Nil & & & & & 500 & 620 & 500 & 350 & 180 & 180 & 250 & 500 & 350 & 500 & 250 & 620 & 620 & 350 & 250 & 250 \\
\hline T. R. & Nil & 250 & 250 & $\overline{180}$ & 100 & 50 & 100 & 180 & 100 & 50 & 125 & 180 & 250 & 250 & 125 & 125 & 125 & 125 & 125 & 100 & 180 \\
\hline M. N. & Nil & 125 & & 180 & 180 & 100 & 50 & 50 & 50 & 50 & 50 & 50 & 50 & 50 & 50 & 50 & 125 & 50 & 50 & 50 & 50 \\
\hline J. F. & Nil & 125 & 250 & $\overline{250}$ & 180 & 250 & 125 & $\overline{350}$ & 350 & 350 & 350 & & & & & & & & & & \\
\hline G. Th. & R.F. & 50 & 50 & 50 & 50 & 50 & 50 & 50 & 50 & 50 & 50 & 50 & 50 & 50 & 50 & 50 & 50 & 50 & 12 & 50 & 50 \\
\hline J. B. & R.F. & & 350 & 620 & 900 & 900 & 620 & 900 & 350 & 250 & 350 & 250 & 250 & 250 & 620 & 350 & 250 & 250 & 350 & 250 & 250 \\
\hline$\overline{\text { C.P.M. }}$ & R.F. & & & & & 500 & 500 & 350 & 350 & 350 & 350 & 250 & 250 & 350 & 250 & 350 & 250 & 250 & 250 & 250 & $\overline{250}$ \\
\hline G. T. & R.F. & & & & & 1250 & 1250 & $\overline{900}$ & $\overline{620}$ & 350 & 250 & 350 & 180 & 180 & & 250 & 250 & 250 & 250 & 180 & 180 \\
\hline J. B. & $\mathrm{Ch}$. & & & 1250 & $\overline{900}$ & 1250 & 900 & 900 & 900 & & & & & & & & & & & & \\
\hline
\end{tabular}


carditis included pericarditis, the appearance of new and significant murmurs (especially an aortic diastolic or a Carey Coombs murmur), convincing electrocardiographic changes, and sometimes the precipitation of congestive cardiac failure without other evident cause. Those remaining were divided into four probable cases of carditis, of which one had rheumatic fever and one had chorea, and seven possible cases, of which four had rheumatic fever and one had chorea.

Except when there were associated signs of rheumatic fever, cases of carditis did not show very high titres. In one (G.Th.) even though there was an associated sore throat and joint pains the titre was low, but this was an unusual case and in most of the others the titre could be regarded as above normal. As will be related shortly, however, the figures were not greatly different from those observed when no rheumatic fever or carditis was present. Therefore it was impossible to correlate the level of the A.S.O. titre to the degree of carditis.

Sometimes the signs of carditis disappeared before the titre fell. This may of course merely indicate that the recognition of continuing carditis is impossible or, on the other hand, that the circulating antigen is being neutralized by increasing production of antibodies and is no longer free to provoke a response in the cardiac tissues. The interpretation is still largely a matter of speculation and will be discussed later.

Fever Not Attributable to the Rheumatic State (Table V). In 11 cases in which there was no evidence of rheumatic fever or active carditis but was fever that was attributed either to a respiratory infection or to some unknown cause, figures ranging from a low normal of 12 to a moderate rise of 350 were noted, as is shown in the five representative cases in Table V. It was difficult to identify the nature of the infection in these cases. It may have been viral in some instances or bacterial in others, and the possibility of some streptococcal invasion could scarcely be excluded by a clinical examination. This is an important group as it is always difficult in a child with recent rheumatism to interpret continued mild pyrexia and it is evident that a moderate rise in A.S.O. does not prove a rheumatic origin.

TABLE V

FeVers that Could not be attributed to the Rheumatic State

\begin{tabular}{|c|c|c|c|c|c|c|c|c|c|c|c|}
\hline \multirow{2}{*}{ Name } & \multirow{2}{*}{ Causes of fever } & \multicolumn{10}{|c|}{ Weeks after onset of disease } \\
\hline & & $0-2$ & $2-4$ & $4-6$ & $6-8$ & $8-10$ & $10-12$ & $12-14$ & $14-16$ & $16-18$ & $18-20$ \\
\hline T. B. & $\begin{array}{l}\text { Respiratory } \\
\text { infection }\end{array}$ & 125 & 180 & 100 & 125 & 250 & 180 & 350 & 180 & 250 & 180 \\
\hline D. G. & , & 12 & 12 & & 12 & & 12 & & 12 & & 12 \\
\hline V. H. &,$\quad$, & 180 & 350 & 180 & 250 & 125 & 250 & 250 & 250 & 250 & 350 \\
\hline B. B. & P.U.O. & 250 & 180 & 50 & 12 & 12 & 12 & 50 & 12 & 12 & 50 \\
\hline P. M. & , & 180 & 250 & 180 & 250 & 125 & 180 & 250 & 250 & 250 & 250 \\
\hline
\end{tabular}

Anti-streptolysin $O$ Titre in Cardiac Failure. In view of the generally accepted opinion that the E.S.R. falls in congestive cardiac failure and therefore no longer represents the degree of activity in the rheumatic state, we thought it important to see whether the same held good for the antistreptolysin $\mathrm{O}$ titre. Eight cases came under this heading, 5 precipitated by bronchitis and 3 by rheumatic carditis. In none of them did we observe any significant change in the titre because of the presence of cardiac failure. 


\section{Discussion}

As a basis for the interpretation of the results set forth, we have accepted the current view that rheumatic fever, including rheumatic carditis, is attributable to an infection with Group A, $\beta$ hæmolytic streptococci (Pauli and Coburn, 1937; Todd, 1932; and others).

The complicated classification and sub-grouping of this streptococcus with the varying types of polysaccharides does not immediately concern us here, and of the soluble products emanating from the organism, our work bears only on A.S.O., which has been more widely studied than the S lysin owing to technical difficulties in the preparation and preservation of the latter.

We have accepted the general view that the variation of other anti-bodies, such as anti-fibrolysin, anti-streptokinase, and anti-hyaluronidase, runs roughly parallel with anti-streptolysin, though we realize that there are exceptions to this, and if it were practical it would be more accurate to have the levels of several antibodies estimated.

It was felt that a study of the anti-streptolysin $\mathrm{O}$ titre levels over a prolonged period might be of value in helping to assess the evidence of activity in carditis, an increasingly important diagnosis to make in studying the natural history of rheumatic valvular heart disease, with the eventual possibility of surgical treatment. Our results do not indicate that the anti-streptolysin values directly help towards this end, though they show that the highest figures are found in rheumatic fever with articular manifestations, agreeing with the observations of Denny et al. (1950). It is common knowledge that carditis may make its appearance during this active stage of articular rheumatism, i.e. at a time when the A.S.O. titre is raised. The presence of a normal titre might, therefore, reasonably be considered as against the presence of active carditis.

On the other hand, when non-cardiac manifestations of rheumatism were absent, the titre was never very high, even though the heart was clearly involved. This point was also made by Denny et al. (1950) and McCarty (1952). Yet although the titre was not very high in this group, it was rarely normal if a figure of over 200 is accepted as abnormal. Here again, therefore, the presence of a completely normal titre weighs against the diagnosis of active carditis.

The reason for a great rise of anti-streptolysin $\mathbf{O}$ titre in articular rheumatic fever with a much less significant rise in cases of carditis is obscure, as is the manner in which the streptococcus causes its effects. Our limited observations do not justify undue speculation in this wide field, but the possibility that a separate antigen-antibody reaction is responsible for the heart lesion might account for lower A.S.O. titre values than when the joints are affected.

This may mean that when articular rheumatism results from streptococcal infection the antistreptolysin rises correspondingly, but that some further mechanism is then set in motion by which the heart may be damaged. If it is assumed that a factor $\mathrm{A}$ is responsible for articular and other non-cardiac rheumatism, and a factor B for the involvement of the heart, factor B might presumably work alone so that carditis could appear without other manifestations of rheumatism. Such a theory might also explain the occurrence of carditis in cases of chorea, but it remains, of course, for further research to show whether two or more factors are concerned and whether they must act synergistically or independently.

\section{SUMMARY}

A study of the anti-streptolysin $O$ titres over a prolonged period in children suffering from manifestations of the rheumatic state has been made. The upper limit of normal has been regarded as 200 units but occasional levels of 250 units were found in apparently healthy children.

The highest titre occurred in cases with joint manifestations. Cases with carditis alone did not show very high titres, though these were in general above normal limits.

Reference is made to the titre in other infections and congestive cardiac failure. The significance of these results is discussed. 
We should like to thank the following for their invaluable assistance in their various fields: Dr. W. K. McGinley of Whiston Hospital, Liverpool, Professor N. B. Capon, Dr. R. W. Brookfield, and Dr. S. E. Keidan; also Dr. H. P. Tulloh, Sister V. Carroll, Mrs. A. Pemberton, and Miss D. Hunt of the Royal Southern Hospital, Liverpool; and finally Sister Mary Joseph and Sister Francis of the St. Joseph's Children's Heart Hospital, Rainhill.

We also acknowledge the grant, kindly made by the Board of Governors of the United Liverpool Hospitals, towards the laboratory expenses for this work.

\section{REFERENCES}

Bywaters, E. G. L. (1951). Brit. med. Bull., 8, 346.

Chaptal, J., Jean, R., Campo, C., Alram, D., and Fraisee, J. (1954). Arch. franc. Pédiat., $11,1055$.

Denny, E. W., Wannamaker, L. W., and Rammelkamp, C. H. (1950). Amer. J. Dis. Child., 80, 506.

Faber, V. (1953). Acta. med. scand., 147, 299.

Long, D. A. (1954). Lancet, 1, 529.

McCarty, M. (1952). Arch. intern. Med., 37, 1027.

Pauli, R. H., and Coburn, A. F. (1937). J. exp. Med., 56, 595.

Poppi, A. (1952). Reumatismo, 4, 242.

Rantz, L. A., di. Caprio, J. M., and Randall, E. (1952). Amer. J. med. Sci., 224, 194.

and, Randall E. (1945). Proc. Soc. exp. Biol., N.Y., 59, 22.

and Rantz, H. H. (1948). Amer. J. Med., 5, 3.

Stollerman, G. H., Lewis, A. J., Schultz, I., and Taranta, A. (1956). Amer. J. Med., $20,163$.

Taranta, A., and Stollerman, G. H. (1956). Amer. J. Med., 20, 170.

Todd, E. W. (1932). Brit. J. exp. Path., 12, 248.

Waksman, B. H. (1949). Medicine (Baltimore), $28,143$.

Windblad, S., Magmross, H., and Wilander, O. (1949). Acta. med. scand., 133, 358. 